\title{
A Conceptual Framework of Facility Management with Artificial Intelligence for Sustainable Smart City
}

\author{
Pujan Neupane ${ }^{1 *}$, Hyunjoo $\mathrm{Kim}^{2}$ \\ ${ }^{1}$ Department of Urban Development and Building Construction, Ministry of Urban Development, Kathmandu, Nepal \\ ${ }^{2}$ International School of Urban Sciences, University of Seoul, Seoul, South Korea
}

\author{
DOI: $10.36348 /$ sjet.2020.v05i10.004 $\quad$ | Received: 21.09.2020 | Accepted: $02.10 .2020 \mid$ Published: 21.10 .2020 \\ *Corresponding author: Pujan Neupane \\ Email: pujan.neupane@nepal.gov.np
}

\section{Abstract}

Most cities under traditional operation mode, which does not use modern communication technologies, are facing urban issues such as energy crisis. To ensure the quality of living in cities, many governments and organizations are coming with different innovative ideas. Recently, the concept of a sustainable smart city has been introduced. Studies have indicated that facility management is the key to achieving sustainability; however, it is challenging to integrate heterogeneous data. The traditional computing tools are inefficient to process big data, and the operating platform for facility management is mostly two dimensional. This research introduces the framework based on GIS-BIM-AI to solve those problems. The framework is applied to energy demand management in the small part of the real city, its prototype is developed, and performance is evaluated where the most important achievement is the development of a smart city operating platform that has single 3D data repository, efficient AI-based urban analytics tools, and powerful 3D visualization with a control centre to visualize, operate and manage facilities. All these features improve the quality of services and citizen's satisfaction, saves resources, time and cost, enhances transparency, and promote public participation in decision making, which are the core principles for sustainability.

Keywords: Facility Management (FM); Sustainable Smart City; Geographic Information System (GIS); Building Information Modelling (BIM); and Artificial Intelligence (AI).

Copyright (C) 2020 The Author(s): This is an open-access article distributed under the terms of the Creative Commons Attribution 4.0 International License (CC BY-NC 4.0) which permits unrestricted use, distribution, and reproduction in any medium for non-commercial use provided the original author and source are credited.

\section{INTRODUCTION}

A Facility management (FM) system can improve the quality of services, provides safety, and enhances the health and comfort of occupants through fast and efficient documentation and management of facilities or infrastructures. The outcome of facility management is lower operating costs by efficient utilization of facilities, detecting risk, and failure that helps in preventing costly repair, and rehabilitation work; thus, it lowers life cycle cost [1]. It also improves communication among stakeholders in transparent decision making for reliability, efficiency, and sustainability. Studies have indicated that facility management is the key to achieving sustainability in a smart city [2, 3]. Costin and Eastman [4] define a sustainable smart urban system as "an application or system that utilizes modern information communication technologies to establish a physical-virtual feedback loop for enabling human-machine-ecological interactions needed to enhance the overall wellbeing of human inhabitants, support the needs of efficient infrastructure systems, optimize the ecological environment, and maintain sustainability goals, all while having the capability to learn user behavior to optimize and improve the system" [4]. The effectiveness of facility management has a significant impact on cost and resource wastages in a smart city; however, most facility managers lack the necessary skills, take time to implement agendas, and often isolated from decision making process that has made their profession undervalued and underappreciated [5,6]. Also, most of the facility management visualization dashboard has a two-dimensional (2D) screen as long as 100 meters. One of the problems with this approach is that it is very difficult to integrate all real-time information within a short time to prevent the failure of a system. Besides, the information generated is mostly $2 \mathrm{D}$ in the form of maps, graphs, images that are difficult to interpret by stakeholders involved in city planning, operation, and management [7]. Only experts or professionals can decipher, so it raises a question on participatory approach and transparency. Furthermore, 
the initial investment, operation, and maintenance costs are high for the 2D dashboard; thus, it cannot be considered sustainable, and there is an increasing concern for the need of three dimensional (3D) visualization tool that can virtually replicate the real world, collects information from city archives, IoT and sensors, performs urban simulation, and quantify the urban analysis qualitatively for the decision makers of the city.

Facility management in a smart city involves multiple stakeholders from top to bottom in the hierarchy. The major actors are government, citizens, institutions, and service providers such as transportation, electricity, internet, and other utility service providers. With so many stakeholders, it can be challenging and complex to coordinate each stakeholder's involvement; therefore, this paper aims to propose a conceptual framework to manage a facility in a smart city i.e. to bring most of the information in a single platform for decision making to attain sustainable development. Chaturvedi et al. [8] highlight the smart district data infrastructure (SDDI) concept that can integrate sensors \& IoT devices, simulations tools, and 3D city models within a common operational framework; however, there has not been any discussion on urban data analysis. Therefore, this study proposes a GIS-BIM-AI framework of FM in smart cities to enhance sustainability. The facility management has been extensively applied for asset management, energy demand management, Mechanical, Electrical, and Plumbing (MEP) system, security, and to detect anomalies in a system such as fire hazards, repair, and maintenance; however, current research is limited to the demonstration of Facility Information Management System (FMIS), and Energy Demand Management. This research also evaluates and validates the GIS, BIM $\&$ AI framework in a small part of a real city. The major research question identified for the development of a conceptual framework for the vision of sustainable smart city development with AI for facility management are:

- How to integrate the GIS, BIM, AI \& IoTs in a single platform for facility management?

- Is the 3D visualization integrated with IoT and AI promotes transparency and communication in decision making?

\section{LITERATURE REVIEW \\ Sustainable Smart City}

Several relevant and recent researches in a smart city has been reviewed. Xue et al. and Liu et al. $[9,10]$ developed a model to evaluate the path for a sustainable smart city. Their research concluded that there are five paths to build a smart city: an effective path to solving "big city disease", encourage open data and information sharing, technological innovation, investment in R\&D, an urban cloud platform for integrated database, and information law to secure information. Agrawal [11] and Michalec et al. [12] investigates the concept of a sustainable city in the case of securing pedestrian safety and climate change respectively. They concluded that the best policies that improve technology, economy, social, and environmental factors ensure a smart and sustainable city. Silva et al. [12] and Costin and Eastman [4] tried to identify the features of a smart city for sustainability and quality of life. In their case study, network facilities and information-sharing technology have been found as the most influential factors in smart city growth.

\section{Urban Data Integration and Data Visualization}

Facility managers still use a 2D operating platform to acquire basic information; however, the information generated contains several symbols, maps, images, and graphs that only experts can interpret, thus there is difficulty in interpretation by stakeholders involved in facility management and raises the concern on transparency [7]. Many researchers are currently proposing and seeking to incorporate Building Information Modeling (BIM) for Facility Management (FM). Wang et al. [14] and Gupta et al. [15] developed a model for urban data integration and successfully demonstrated in a 2D framework; however, their work needs to be extended to a 3D framework for successful implementation of a smart city. The application of 3D visualization based on GIS and BIM has been studied by several researchers. Ma and Ren [16] studied 41 researches on Planning and Design, construction, operation and maintenance, and demolition; however, integrated application for the whole life cycle and its validation is still lacking in practice. Correa [24] highlights the need for upgrading BIM tools with Big Data Analytics.

\section{Application of AI in Facility Management}

Several scholars $[17,18,19,20]$ found that machine learning (ML) algorithms such as Artificial Neural Network (ANN), and Random Forest (RF) have both computational efficiency and accuracy in predicting energy consumption, stock market, anomaly detection, cyber-attack, predictive maintenance, and facility management. Baird et al. [21] studies the costeffectiveness of ML/AI in an underground water supply distribution network and found that if $\mathrm{AI} / \mathrm{ML}$ would have used then there will be 4 miles less replacement in a network having 847 miles pipelines and would have saved \$4M. Goulden and Spence and Curtis et al. studied the role of Facility Managers, and they suggested adopting tools to strengthen the ability of facility managers $[5,6]$. Cao et al. and Carvalho et al. $[22,23]$ studied the application of AI in facility management; however, many assumptions were done and relied on qualitative factors rather than on rich data.

\section{Research Gap}

Although, many kinds of research have been done in smart city solutions, transforming it into the real world is very tedious and complicated; therefore, a more systematic approach for transparency and public 
participation is needed for a sustainable smart city. Moreover, despite these studies, there still exists a gap to integrate heterogeneous data with efficient analysis tools for early warning and decision making. Correa [Error! Reference source not found.] highlights the need for upgrading BIM tools with AI to innovate a smart city development in the 4th industrial revolution. Chaturvedi and Kolbe [25] recommended extending the 3D model with time-dependent data from IoT, sensors, etc. Since the efficiency of AI depends on the quality of data, Carvalho et al. [26] recommended integrating ML with the latest sensors for improved data, unnecessary replacement, safety, efficiency, and economy. Recent researchers have highlighted the importance of the Digital Twin (DT) platform for sustainable smart city development; however, questions that need to be answered include the role of DT or virtual city in the built environment, type of sensing technologies to precisely capture the data, type of models to process the big data collected through a project's lifecycle, and seamless interoperability among heterogeneous applications [27, 28].

\section{METHODOLOGY}

The set up for the current study as shown in Figure 1 has been hypothesized by previous researchers $[27,28]$, which has the characteristics or requirements of digital twin based sustainable smart city i.e., a reflection of physical space in virtual space with real-time monitoring, scenario modeling, simulation and analytics with powerful visualization platform. The research is designed into three parts: development of a prototype, it's validation, and evaluation.

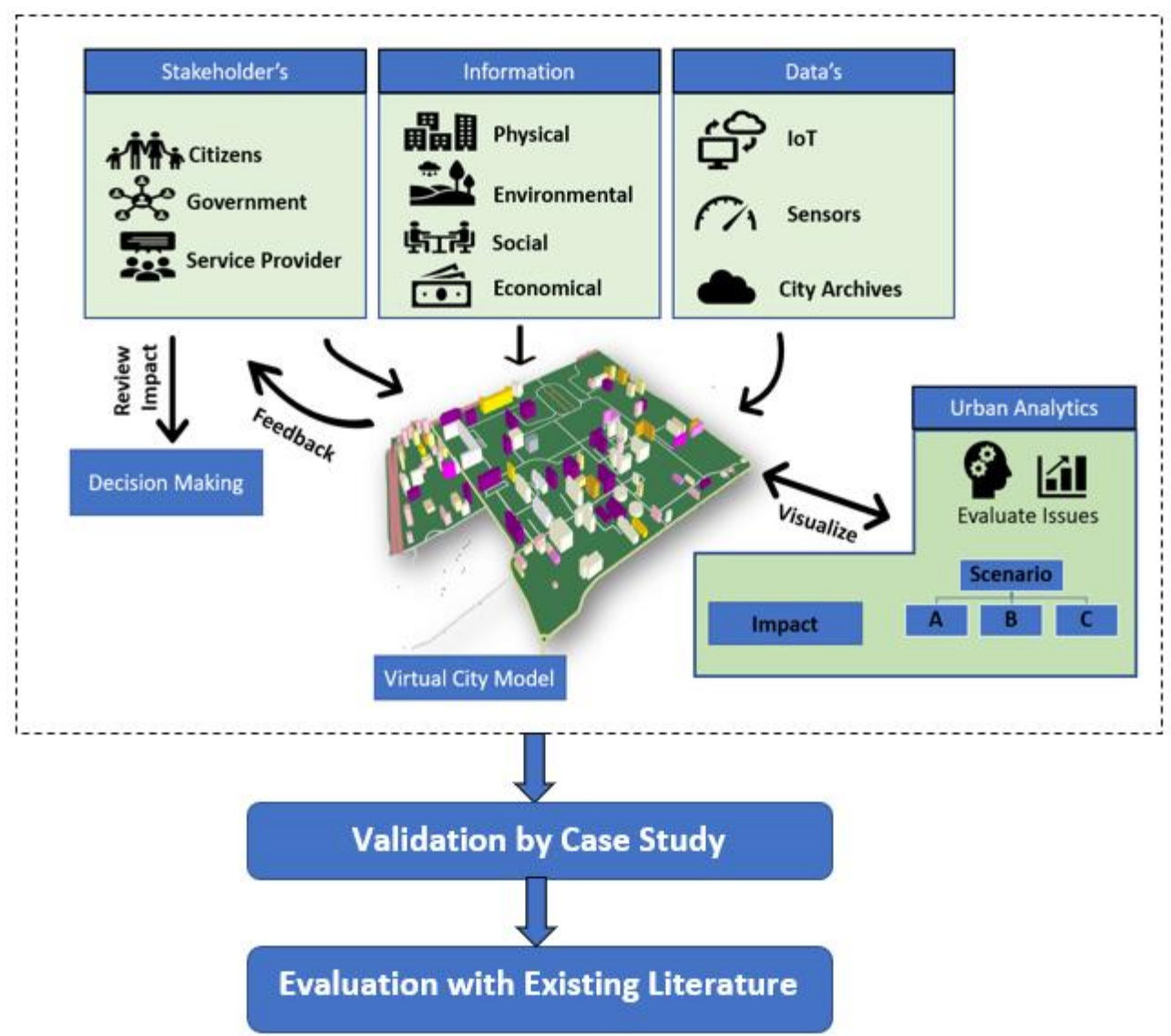

Fig-1: Research Methodology

\section{Development of Prototype for Facility Management with AI in Smart City}

The smart city operating platform, for instance, for facility management will be constructed by using network technology, database technology, GIS technology, BIM technology, and urban analytical tools based on AI technology. The proposed digital twinbased prototype, as shown in Figure 2 has four layers that resemble the real smart city. 


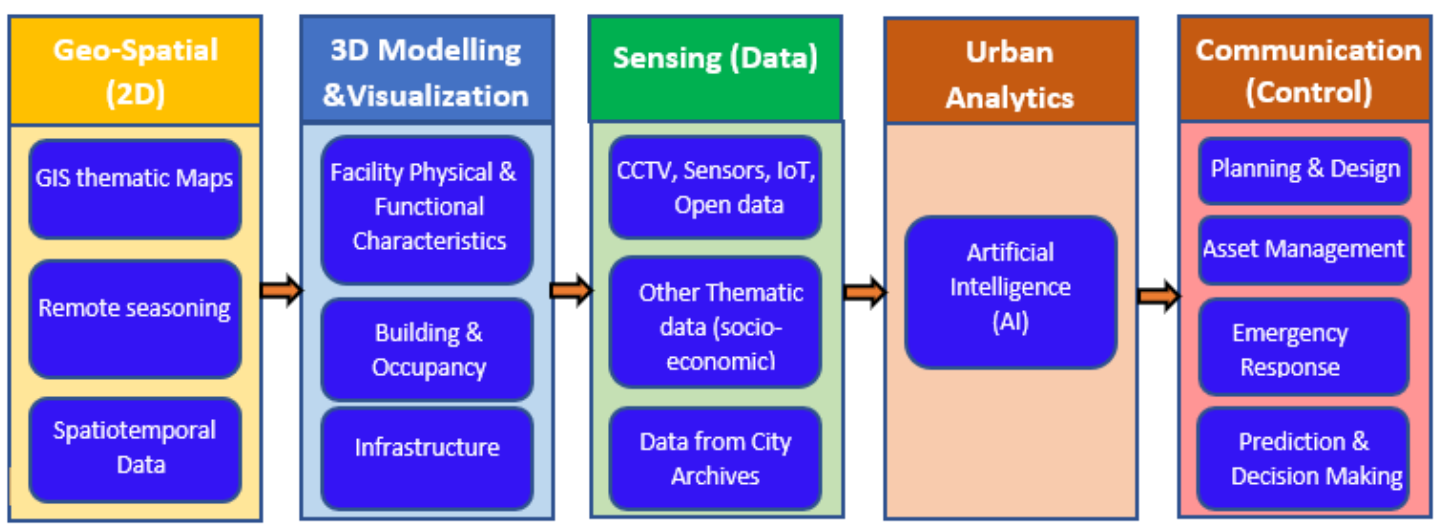

Fig-2: Framework for development of Prototype for Facility Management in Smart City (GIS-BIM-AI Framework)

\section{Physical Layer}

The physical layer is a prerequisite for a smart city project that virtually represents the physical infrastructures of a real city. To develop a physical layer, the first step is data acquisition. The spatial data such as points, lines, and polygons can be obtained by various sources such as direct engineering survey, satellite images, remote seasoning, GIS maps, and so on. It will be used to understand and especially model the outdoor environment of a smart city. The GIS (2D) information is exported to the BIM-based 3D platform. In the 3D platform, all the physical \& functional characteristics of facilities and its components are modeled. The BIM can extend the scope of the GIS and process the micro-level data. The BIM data are mostly facility information such as dimensions, material, type, and interior details in case of buildings. The whole procedure is called GIS-BIM integration. Here, a 2D GIS data is integrated with facilities properties to develop a 3D virtual city model that digitizes the information.

\section{Sensing Layer}

The second layer consists of a sensing layer that collects data from multi-dimensional sources. ICT \& IoT connects city administrators and facility managers to directly interact with the public, community and the city infrastructure to monitor what is happening in a city, how a city is evolving, and how to enable a better quality of life. The data are collected from citizens and devices using sensors integrated with a real-time monitoring system and then processed for analysis. The data, for instance, is collected from local weather and climate stations, regional weather radar, and smart meters for energy, gas, and water consumption, video cameras, and traffic sensors. Similarly, other information includes historical data and data released from different organizations such as social, economic, financial, and other management information. The GIS-BIM model integrated with the real-time database and historical database visually, digitally represents graphical and non-graphical information in a single platform, and systematically organize the information flow. Now, the 3D virtual city model perceives how a city is operating.

\section{Urban Analytics Layer}

The third layer is the urban analytics layer and used for data analysis, forecasting, and prediction of complex phenomena; however, the heterogeneity and the uncertainty of data require a considerable amount of computational time, making traditional analytical tools unsuitable for real-time applications. The traditional computational programming such as spreadsheet is inefficient and unreliable for accurate urban data analysis to solve urban problems, and to provide a wellinformed intelligent decision, so, the urban analytics layer is designed to use $\mathrm{AI} / \mathrm{ML}$ tools that can learn patterns and relationships of data from a historical database, adapt, innovate, and thereby respond more effectively and promptly to changing circumstances by improving the intelligence of facility. The artificial intelligence not only makes more efficient use of physical infrastructure/ facilities, and other resources but also uses data analytics to support multidimensional information for robust economic, social, and cultural development through prediction, automation, and decision support. The prediction from $\mathrm{AI}$ is also useful to evaluate the real-time data from a sensor in case of an emergency to prevent losses. The proposed urban analytics tools can evaluate the urban issues, creates a scenario (what-if), determines the impacts of scenarios, for example, estimate the energy demands or potentials of solar energy production for all buildings, simulate road traffic and pedestrian flows, or perform noise propagation or flooding simulations, and sends feedback to stakeholders for decision making. The impacts of interaction or communication are integrated with the virtual city model and can be visualized qualitatively and quantitatively that allows users to interact with the various components in a city.

\section{Control \& Communication Layer}

The Control and Communication layer is designed to evaluate the feedback derived from the physical layer, sensing layer, and quantitative impact modeling from the urban analytics layer. It uses technology and prepares appropriate visualizations for multidimensional stakeholders as input for decision making. It develops an interactive 3D virtual model of the city integrated with real-time data and urban 
analytics toolkits for well- informed decision making, and an early impact assessment. This layer is developed by integrating the 3D model developed from GIS-BIM with dynamic and static data, and urban analytical tools. The whole procedure constitutes GIS-BIM-AI integration. The visualization tools can quantify the result of the urban analytics layer interactively. The control \& communication layer is divided into three parts:

(1) Rule-Based Modelling: In rule-based modeling, logical are used to design filters on the data, or to build queries. In this research, the concept is demonstrated to filter the building by floor area, heights, and occupancy type, for example, the height of building $>15 \mathrm{~m}$. The impact of communication or command is virtually displayed in the 3D city model. The information generated is usually in the simpler form such as colors, images, and notification that can be useful not only for the city officials but also for the service providers and citizens for well-informed decision making in managing the facilities.

(2) Impact Modelling: The impacts of data analysis and scenario analysis done in the urban analytical layer are virtually demonstrated in the $3 \mathrm{D}$ city model, then the stakeholders discuss whether the impact meets their requirements for decision making. The impact analysis generally is a predictive model from the urban analytical layer, and it is useful to identify problems, and creating a scenario of the event for well-informed decision making.

(3) Dynamic Modelling: It consists of both empirical-statistical elements and rule-based modeling aspects. It is designed to automatically detect anomalies or outliers from the data set and send command or information to prevent the failure of the system. The commands may include information sharing, alerts, and beep for uninterrupted services. For example,

- If predicted Energy Consumption (from urban analytic layer)-Ep

- Actual Energy Consumption (from sensors, i.e dynamic data)-Ea
- If $\mathrm{Ea} \neq \mathrm{Ep}$ and falls outside the confidence interval or crosses the threshold value, then the system detects an anomaly and sends information to stakeholders to prevent failure of the system.

\section{CASE STUDY \& VALIDATION}

In this section, the proposed methodology i.e. Integration of GIS-BIM-AI is validated. The concept is applied in the small part of the real city, its prototype is developed by the proposed framework and the performance is measured with standard parameters. This section consists of a selection of the study area, the scope of the research, and the process of data collection, analysis, and interpretation. The GIS-BIM-AI is validated on the Facility Information Management System (FMIS), and energy demand management.

\section{Study Area}

The model city for demonstration is Singh Durbar, which is the Integrated Governmental Building Complex in Kathmandu, the capital city of Nepal. It is geographically located around $27^{\circ} 41^{\prime} 53.77^{\prime \prime} \mathrm{N}$ and $85^{\circ} 19^{\prime} 30.91^{\prime \prime} \mathrm{E}$ with an area of 42 ha. All the ministries of the Government of Nepal are on the premises of Singh Durbar. After the successful implementation in the model city, it can be extended and scalable to the city level.

\section{Data Collection}

The heterogeneous data as per the availability and the scope of work are collected from various sources, and some of the outliers are removed. The types and sources of data collected are as follows:

Geospatial Data: The 2D Geospatial data is collected from the Open Street Map and Master plan. The building footprints of 188 buildings acquired from Open Street Map is only considered for this study, and some adjustment is made according to Master Plan.

Building Information: This data set consists of all details of government buildings in the model city. The properties of buildings are collected from 2D drawings provided by the Ministry of Urban Development, Nepal. The attributes for building inventory are presented in Table 1 .

Table-1: Attributes for Building

\begin{tabular}{|l|l|}
\hline Parameters & Description \\
\hline Building Information & Name of Building, Type \& Location \\
\hline Overall Height & Height of building $(\mathrm{m})$ from basement to roof level \\
\hline Total Floor Area & Total floor of building $\left(\mathrm{m}^{2}\right)$ including basement area \\
\hline Wall Area & Total surface area of building $\left(\mathrm{m}^{2}\right)$ \\
\hline Roof Area & Roof area $\left(\mathrm{m}^{2}\right)$ both accessible \& non-accessible \\
\hline Wall Thickness & External wall thickness $(\mathrm{m})$ \\
\hline Opening Area & Total glazed area of the building $\left(\mathrm{m}^{2}\right)$ \\
\hline U-Value: Ur \& Uw & Thermal transmittance value $\left(\mathrm{W} / \mathrm{m}^{2} . \mathrm{K}\right)$ for roof and wall \\
\hline
\end{tabular}


Pujan Neupane \& Hyunjoo Kim., Saudi J Eng Technol, October, 2020; 5(10): 366-381

Sensor Data: To demonstrate the concept of real-time data integration in the $3 \mathrm{D}$ model, the following information is assumed to be from real-time observation from sensors.

Sensor 1: Monthly Energy Consumption (KWh): The data for monthly energy consumption (electricity) is collected from the energy meter of seven buildings. The data is provided by the Nepal Electricity Authority.

Sensor 2: Weather Data: The weather data is extracted from the Report on Solar Resource and Photovoltaic Potential of Nepal, published from the World Bank (https://datacatalog.worldbank.org), and the attributes are enlisted in Table 2. Figure 3 and Table
3 show data distribution and sample datasets respectively.

Tools

The software application used for data collection and analysis are as follows:

- Geo-Spatial: Open Street Map \& QGIS

- 3D Modelling \& Visualization: Sketch Up ver. 2018.

- Urban Data Analytics: Machine Learning Software

○ Visual Gene Developer 1.9: Artificial Neural Network

○ Weka 3.8: Random Forest

- Visualization, communication \& control Dashboard: SketchUp User Interference

Table-2: Attributes for Weather

\begin{tabular}{|l|l|}
\hline Parameters & Description \\
\hline GHI & Global horizontal irradiance $\left(\mathrm{W} / \mathrm{m}^{2}\right)$ from thermopile pyranometer \\
\hline Air Temperature & Air temperature $\left({ }^{\circ} \mathrm{C}\right)$ at $2 \mathrm{~m}$ height \\
\hline Relative Humidity & Relative humidity $(\%)$ at $2 \mathrm{~m}$ height \\
\hline Wind Speed & Wind speed $(\mathrm{m} / \mathrm{s})$ at $10 \mathrm{~m}$ height \\
\hline Wind Direction & Wind direction in degrees north, counted clockwise \\
\hline Barometric Pressure & Ambient air pressure in $\mathrm{hPa}$ \\
\hline Rain & Liquid precipitation in $\mathrm{mm}$ \\
\hline
\end{tabular}

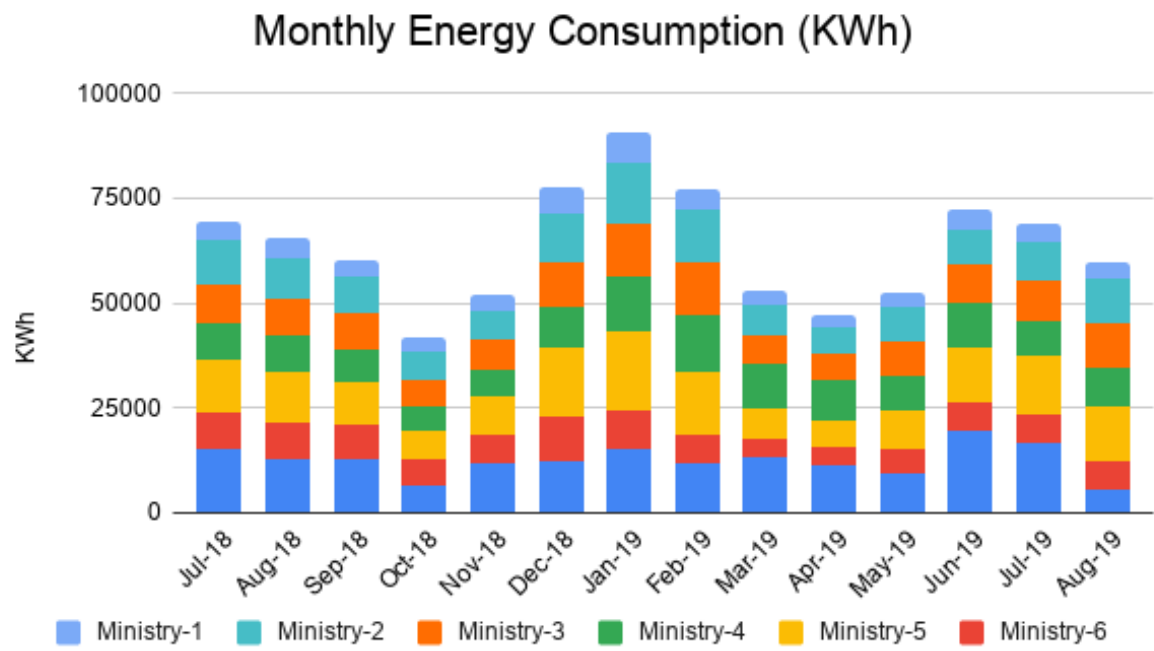

Ministry-1 Ministry-2 Ministry-3 $\square$ Ministry-7
$\square$ M

Fig-3: Monthly Energy Consumption

Table-3: Sample Dataset

\begin{tabular}{|c|c|c|c|c|c|c|c|c|c|c|c|c|c|c|c|}
\hline GHI & $\begin{array}{l}\text { air } \\
\text { temp }\end{array}$ & $\begin{array}{l}\text { Relative } \\
\text { Humidity }\end{array}$ & $\begin{array}{l}\text { wind } \\
\text { speed }\end{array}$ & $\begin{array}{l}\text { wind } \\
\text { direction }\end{array}$ & $\begin{array}{l}\text { barometric } \\
\text { pressure }\end{array}$ & $\begin{array}{l}\text { Precipi } \\
\text { tation }\end{array}$ & $\begin{array}{l}\text { overall } \\
\text { height }\end{array}$ & $\begin{array}{l}\text { Total } \\
\text { Floor } \\
\text { Area }\end{array}$ & $\begin{array}{l}\text { wall } \\
\text { area }\end{array}$ & $\begin{array}{l}\text { roof } \\
\text { area }\end{array}$ & $\begin{array}{l}\text { Wall } \\
\text { Thickness }\end{array}$ & $\begin{array}{l}\text { Opening } \\
\text { Area }\end{array}$ & Uw & $\mathrm{Ur}$ & $\begin{array}{l}\text { Electricity } \\
\text { Consumption }\end{array}$ \\
\hline 182.6 & 24.12 & 83.45 & 0.85 & 126.28 & 859.95 & 0.01 & 20.45 & 3547.25 & 2166.5 & 766.7 & 0.27 & 757.55 & 2 & 2.07 & 8729 \\
\hline 182.6 & 24.12 & 83.45 & 0.85 & 126.28 & 859.95 & 0.01 & 17.75 & 3886.71 & 2166.5 & 766.7 & 0.24 & 757.55 & 1.9 & 1.08 & 15067 \\
\hline 182.6 & 24.12 & 83.45 & 0.85 & 126.28 & 859.95 & 0.01 & 17.75 & 3547.25 & 2645 & 920.1 & 0.25 & 901.08 & 2.8 & 3.44 & 12866 \\
\hline$\ldots$ & $\ldots$ & $\ldots$ & $\ldots$ & $\ldots$ & $\ldots$ & $\ldots$ & $\ldots$ & $\ldots$ & $\ldots$ & $\ldots$ & $\ldots$ & $\ldots$ & $\ldots$ & $\ldots$ & $\ldots$ \\
\hline
\end{tabular}


Prototype Development for Facility Management

The simplified workflow for the GIS-BIM-AI

framework for facility management in a smart city developed by the proposed methodology is illustrated in Figure 4. The prototype has four layers.

\section{Physical Layer Development for Facility Management}

In this layer, the Geospatial Data, the 2D building footprint from the Open Street Map (GIS map) is extruded by its height in the BIM platform i.e., SketchUp that is shown in Figure 5. The SketchUp is integrated with Ruby script, which is user friendly and easy to work where the users can develop $3 \mathrm{D}$ with the desired level of details (LOD) and adds information to the $3 \mathrm{D}$ model in a short time. In this study, the buildings are modeled as objects in LOD1 due to the limitation of data and time. The GIS-BIM integration develops a virtual 3D city model, and this interactive platform is the prerequisite for FM in a smart city.

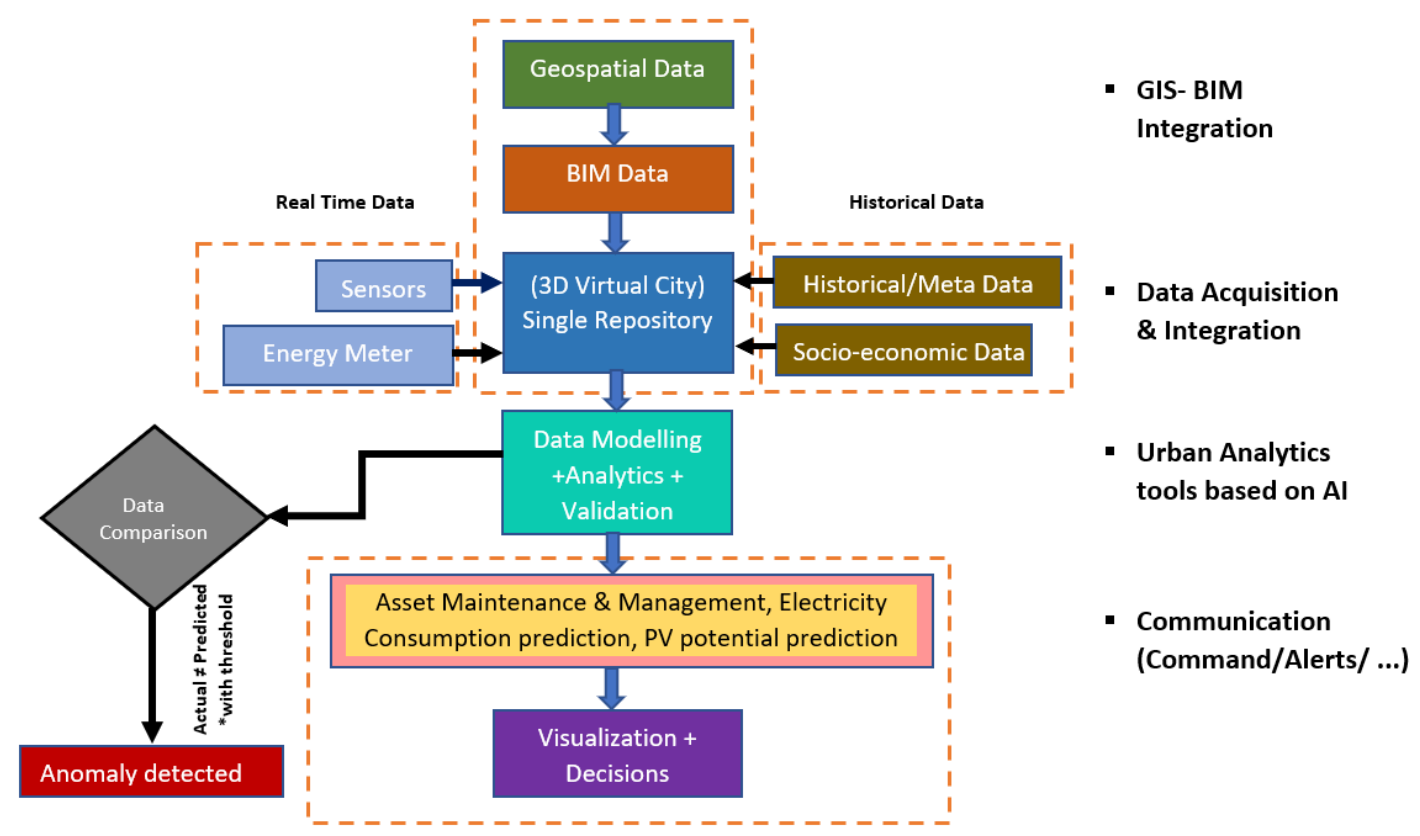

Fig-4: Framework for Facility Management in Smart City

\section{Sensing Layer for Facility Management}

This layer adds historical graphical \& nongraphical data and other real-time or dynamic data from IoT \& sensors to Physical Layer or 3D city model by Ruby script. The components used for the demonstration are:

(1) Facility Information: It consists of information about building attributes.
(2) Sensor Observation 1: Energy Meter for Electricity Consumption, the assumption is made that it retrieves real-time observation from smart energy meter installed in buildings.

(3) Sensor Observation 2: It allows the users to retrieve a real-time observation from a weather station located in the Institute of Engineering.

(4) Historical Data: It consists of historical records of Electricity Consumption \& Weather.

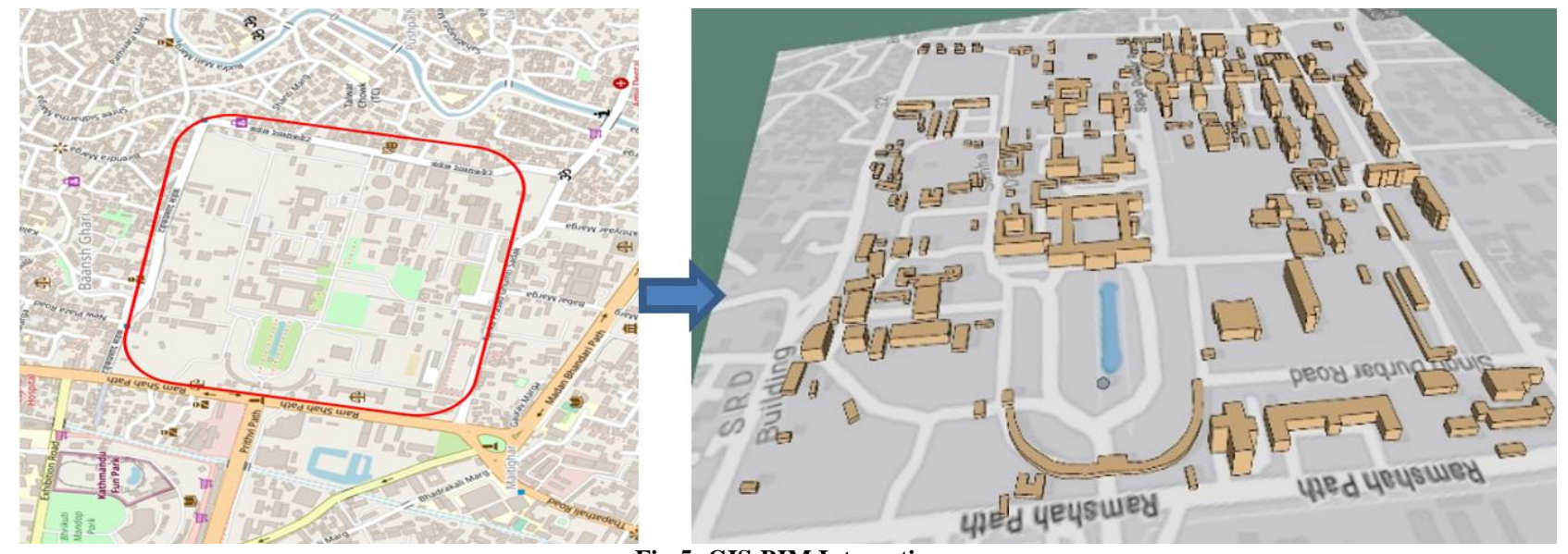

Fig-5: GIS-BIM Integration 
The Ruby code used for the demonstration of the facility management information system (FIMS) and Energy Demand Management is included in Annex. When the users click any 3D model of the buildings then the virtual building model will interact by displaying the information incorporated into it as demonstrated in Figure 6.

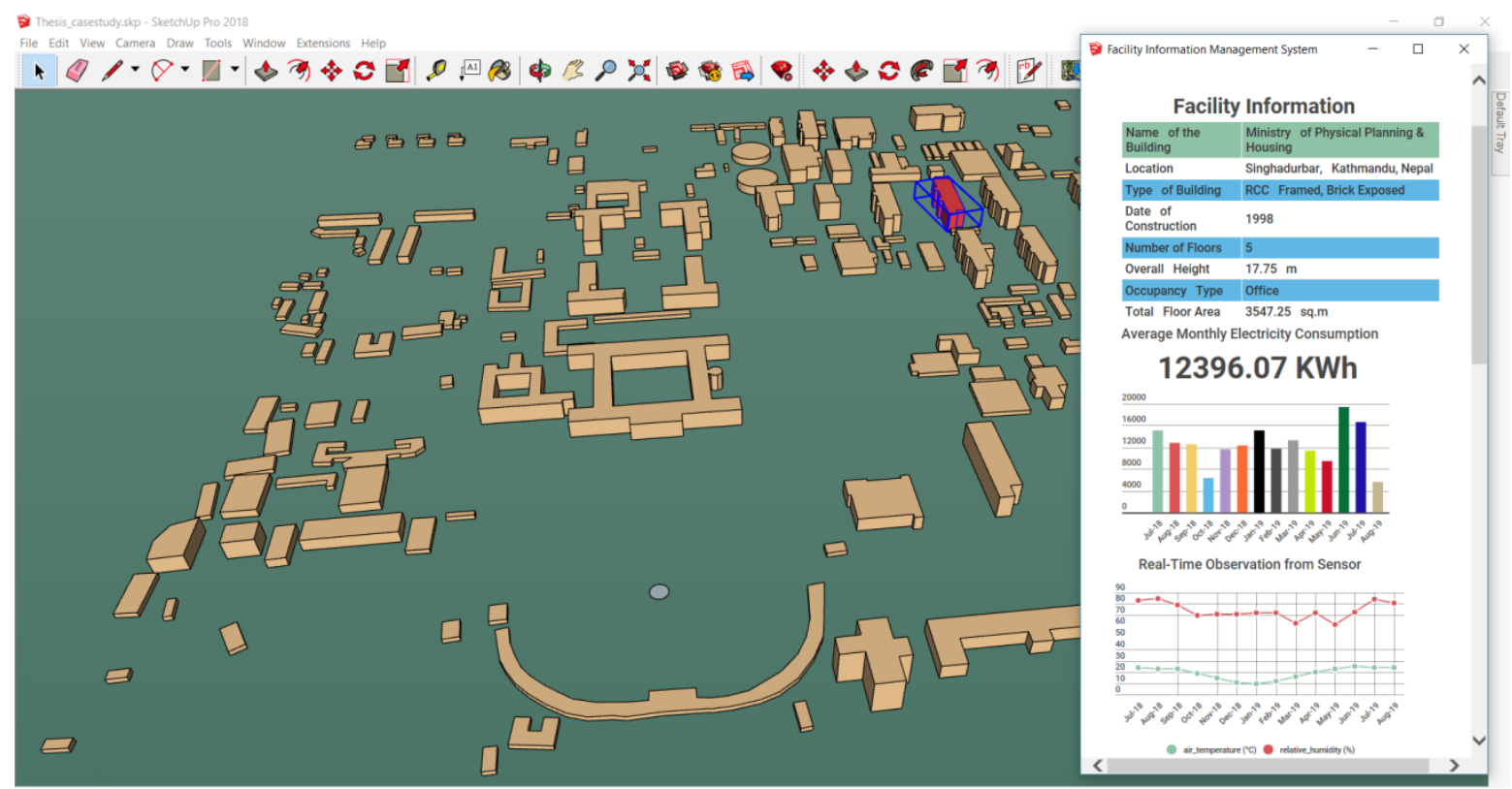

Fig-6: Facility Information System (A single 3D virtual city repository)

\section{Urban Analytics Layer for Facility Management}

In this study, the applications of two machine learning algorithms: Artificial Neural Network and Random Forest are studied to develop the predictive model for energy consumption since several researchers have demonstrated the application of ANN and RF in energy prediction $[17,19,20]$. The purpose of data analysis in this study is to demonstrate the process in the proposed framework rather than rigorous data analysis and interpretation; however, efforts have been made to achieve accurate and reliable data analysis. Figure 7 illustrates the process of model building into three major stages: Optimization, Training, and Validation. Finally, a performance evaluation is done for reliability.

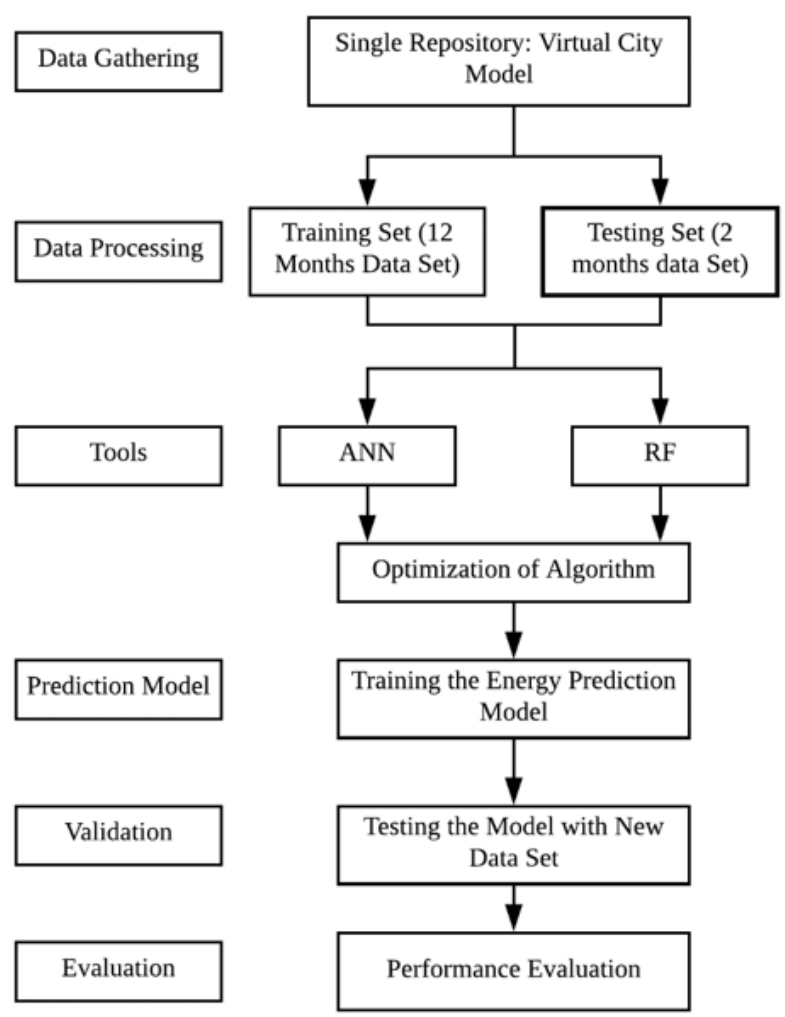

Fig-7: Flow chart for Urban Analytics 
Stage 1: Optimization of the Algorithm: The algorithm is optimized until the training error and testing error is minimized. The parameters having the minimum training error and testing error are selected as the optimum configuration to develop a predictive model. As far as possible, the default value is considered as optimum.

\section{Table-4: Summary of Optimization for ANN}

\begin{tabular}{|c|c|}
\hline Parameter & Value \\
\hline Cycle & 2500 \\
\hline No. of Neuron & 10 \\
\hline No. of Hidden Layer & 3 \\
\hline Transfer Function & Hyperbolic Tangent \\
\hline Moment Coefficient & 0.5 \\
\hline Learning Rate & 0.01 \\
\hline
\end{tabular}

Table-5: Summary of Optimization for RF

\begin{tabular}{|l|c|}
\hline Parameter & Value \\
\hline Cycle & 100 \\
\hline Depth & 0 \\
\hline No. of Features & 7 \\
\hline
\end{tabular}

Stage 2: Training the Model: In this study, the ML algorithm is trained to learn from the historical dataset of Energy Consumption of seven buildings to predict the future scenario in the city. The ANN and RF are trained with the parameters shown in Table 4, and Table 5 respectively, and the performance is evaluated. Figure 8 compares the performance of the training model between ANN and RF.

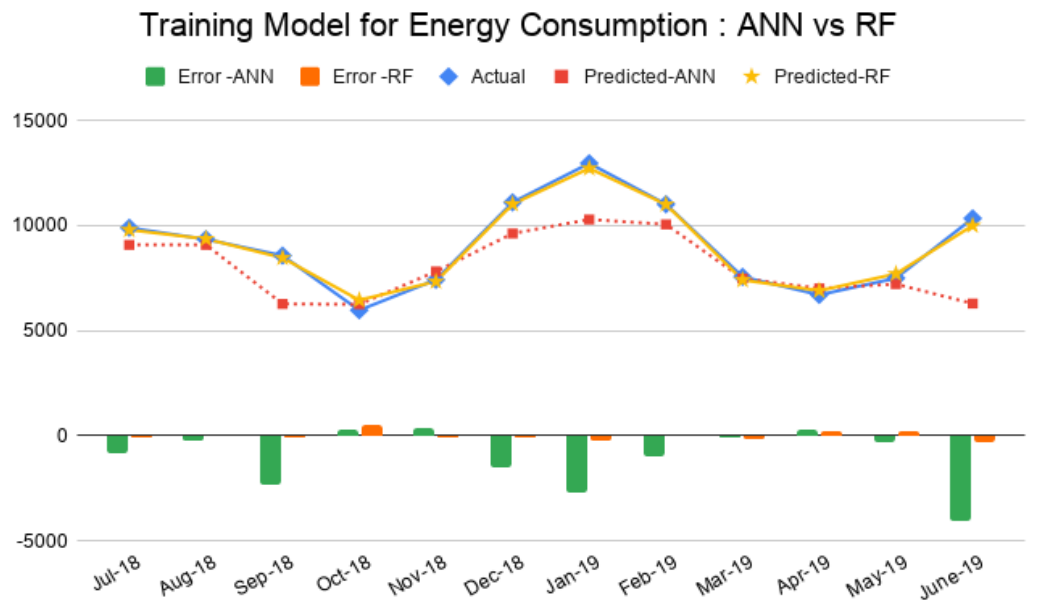

Fig-8: Performance of Training Model (ANN vs RF)

Stage 3: Validation: Figure 9 compares the performance of ANN and RF models in predicting the energy consumption on the test dataset. Table 6 summarizes the performance of the model. The results are consistent with previous studies [17, 19, 20]. In this case study, both RF and ANN have demonstrated them as valuable machine learning tools to predict building's energy consumption; however, Random Forest was found to be easy in optimization and shows higher accuracy in both training and testing for a given dataset with computing time is less than $1 \mathrm{~s}$ and the speed of 1353 data/sec. This technique has the potential to outperform the previous computing methods such as spreadsheets for heterogeneous urban data.
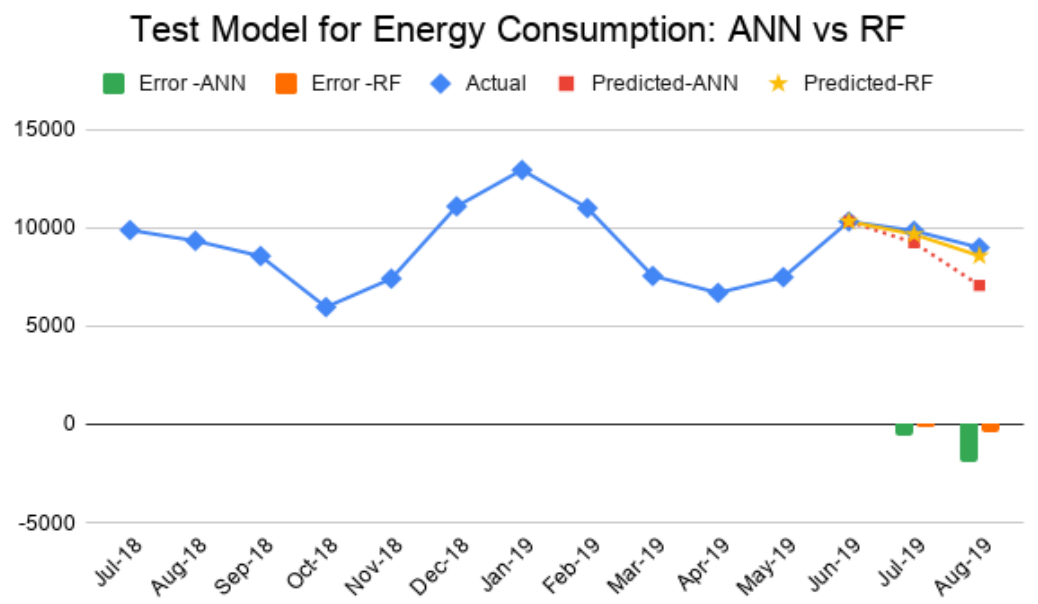

Fig-9: Performance of Test Model (ANN vs RF) 
Pujan Neupane \& Hyunjoo Kim., Saudi J Eng Technol, October, 2020; 5(10): 366-381

Table-6: Performance Evaluation

\begin{tabular}{|l|l|l|l|l|}
\hline Evaluation Parameter & ANN (Train.) & RF (Train.) & ANN(Test) & RF (Test) \\
\hline Mean Absolute Error & $1155.53 \mathrm{KWh}$ & $167.61 \mathrm{KWh}$ & $1263.61 \mathrm{KWh}$ & $49.96 \mathrm{KWh}$ \\
\hline Root Mean Square Error & $1658.81 \mathrm{KWh}$ & $735.89 \mathrm{KWh}$ & $1423.79 \mathrm{KWh}$ & $455.52 \mathrm{KWh}$ \\
\hline Relative Absolute Error & $12.80 \%$ & $1.86 \%$ & $13.40 \%$ & $3.18 \%$ \\
\hline Relative Square Error & $3.22 \%$ & $0.05 \%$ & $2.28 \%$ & $0.12 \%$ \\
\hline $\mathrm{R}^{2}$ & 0.561 & 0.993 & - & - \\
\hline Time & $14.00 \mathrm{~s}$ & $0.09 \mathrm{~s}$ & - & - \\
\hline Speed & $96 \mathrm{data} / \mathrm{sec}$ & $1353 \mathrm{data} / \mathrm{sec}$ & - & - \\
\hline
\end{tabular}

Figure 10 shows the predictive model for energy consumption for ANN and RF respectively. Figure 11 shows that the most significant variables for energy consumption in the modal city as per the available data are building components: wall thickness, Uw, Ur, and total floor area. A significant negative correlation is found between the wall thickness and the energy consumption of the buildings. The energy consumption is also strongly dependent on the thermal transmittance of the wall and roof. The AI-based analysis easily provides performance of insulation materials, walls, roof and so on in relation with other variables such as weather that helps facility managers to understand how the building is consuming the energy in relation with other factors such as environmental and material properties and what can be done to save energy. Secondly, the urban analytics result also shows that the total floor area also has a moderate influence on energy consumption, so this suggests that there must be optimum use of spaces for energy-efficient buildings. These are some of the immediate fields where the facility manager can retrofit to make an energy-efficient city. Surprisingly, the negative correlation of solar radiation and air temperature could be explained by a decrease in solar radiation or temperature could increase the heating demand. Facility managers need to consider the several variables in a specific time in a building and make appropriate decisions in energy management; however, machine learning effectively looks at when should we be aware of load increases on a building and how should we act and be proactive ahead of these load increases, for example, if the ambient temperature lowers in the case of Kathmandu, then the system assumes that heating load is increasing. AI helps the facility manager to anticipate the situation and helps to respond quickly and efficiently that save money, time, and control the buildings to enhance the safety and comfort of occupants.
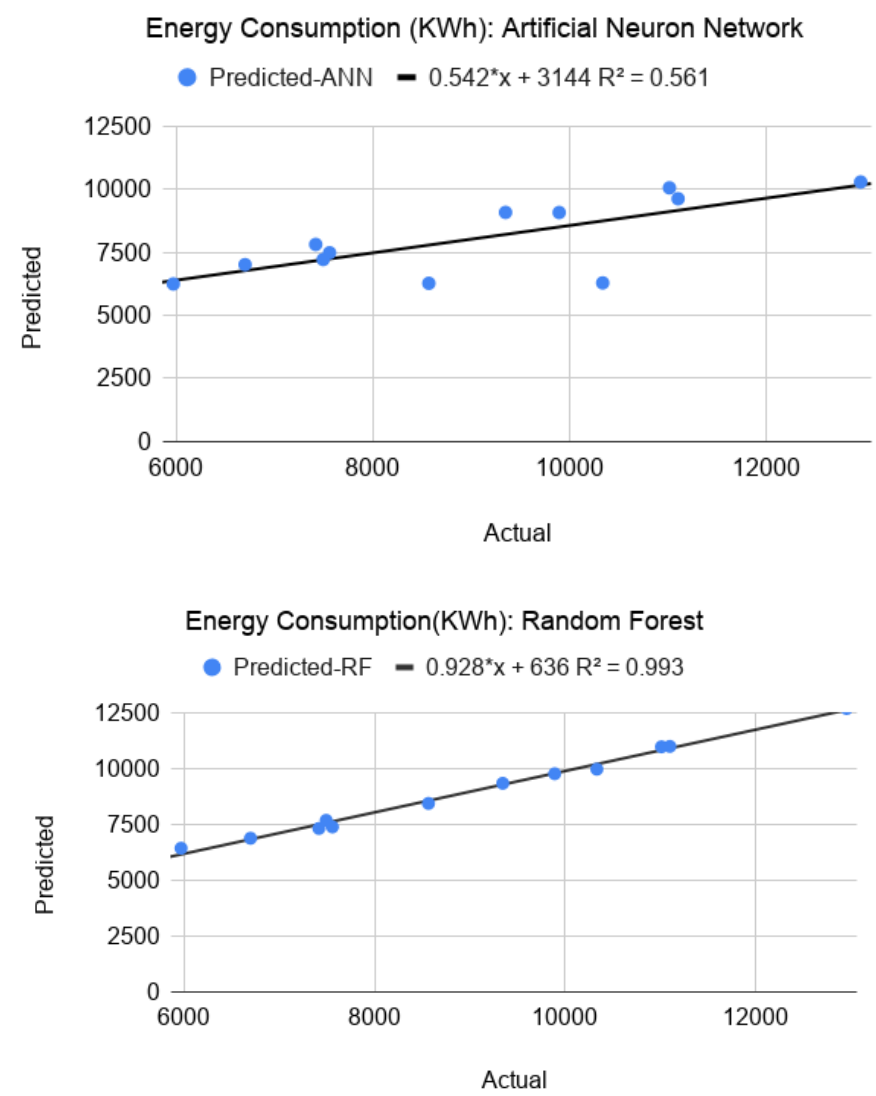

Fig-10: Predictive Model for Energy Consumption by ANN and RF 


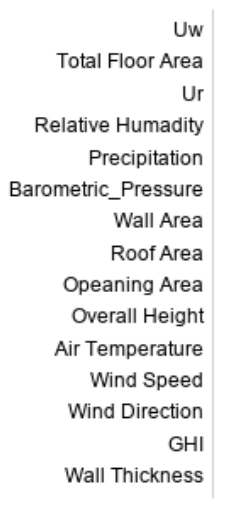

$-0.75$

\section{Variable Importance Factor}

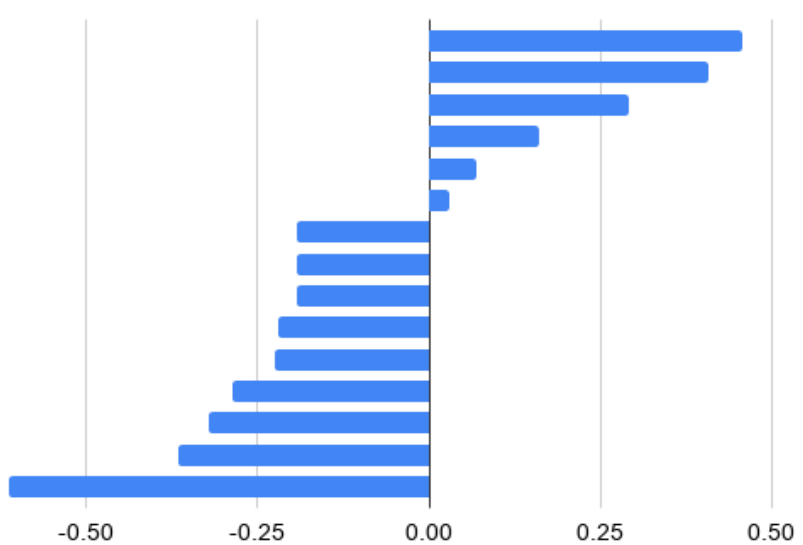

Fig-11: Importance Factor of Variables
In recent years, optimization of construction and building energy usage has been received considerable attention, as this sector is known as the main contributor to air pollution and fossil energy consumption; however, the traditional modeling of building energy using software and statistical approaches does not satisfy the demand for fast and accurate forecasting, which is essential for decisionmaking systems. ML models through these case studies have shown great potential as an alternative solution for the energy modeling and assessment for the energy use of buildings. AI develops a true cognitive that will be constantly learning about the building's behavior and performance to understand and predict energy use for each building and define the relationships between variables. But most importantly, AI can provide information to the people who use the buildings daily and help to make them more productive, whatever their job in a very short time. The evidence from this study has highlighted the significant roles played by AI in making well-informed decisions by facility managers and stakeholders such as building owners and service providers for a smart and sustainable city.

\section{Control \& Communication Layer for Facility Management}

The Control and Communication layer is developed by integrating the GIS-BIM model with AI in SketchUp 2018 user interface. For, the purpose of the demonstration, the concept is applied in the Facility Information Management System (FMIS) and energy demand management, and the effectiveness of visualization is discussed. The Control \& Communication layer is divided into three parts:

(1) Rule-Based Modelling: Ruby Console is used for data management and analysis in the SketchUp, Figure 12 shows the result of rulebased modeling, which pinpoints the exact location of the building having a maximum height in red color and building having a minimum height in yellow color in the built-up environment. This operating platform provides visual information to the facility managers and stakeholders on how their city is evolving in the simpler form within a short time. The simplicity and clarity of the information generated from this platform encourage stakeholder participation and promote transparency for well-informed decision making.

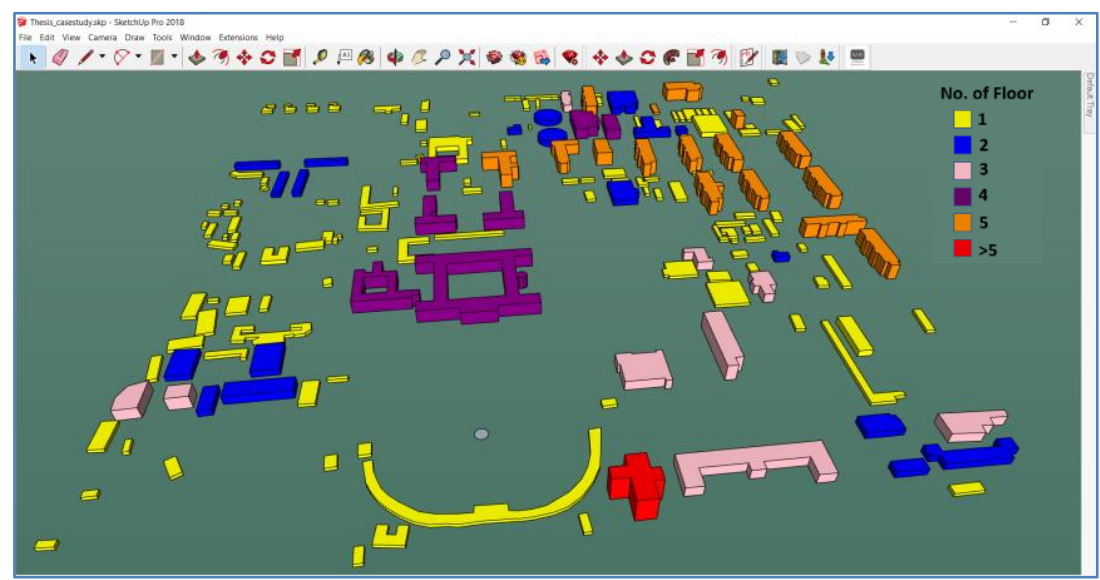

Fig-12: Visualization of Buildings by Height 
(2) Impact Modelling: The data for impact analysis is acquired from the 3D city single repository that is developed by integrating the physical layer and sensing layer. The Ruby script for the visualization of the current energy consumption of buildings is the same as visualization of the building by height. In this research, the impact of weather and building properties on the energy consumption i.e. the problem is virtually demonstrated in the virtual city model as shown in Figure 13. The impact or interaction, which is usually in a complex quantitative form, is transformed into a qualitative form that is represented by the color. The four types of energy consumption conditions of the facility are used for interpretation: Low, Medium, High, and Very High, and the types of colors are green, slate blue, gold, and dark red respectively. Facility managers and other stakeholders having different background can easily interpret the result and understands how their city is consuming energy. Figure 14 shows the integration of AI tools into the 3D city model. The integration is done with the help of Ruby script. To illustrate the application of AI in the 3D city model, let's consider the situation what-if the stakeholders want to know the energy consumption of all buildings at the city level. For this study only energy consumption details of seven buildings are available; therefore, the predictive model for energy consumption in the urban analytics layer is developed from the database of seven buildings.

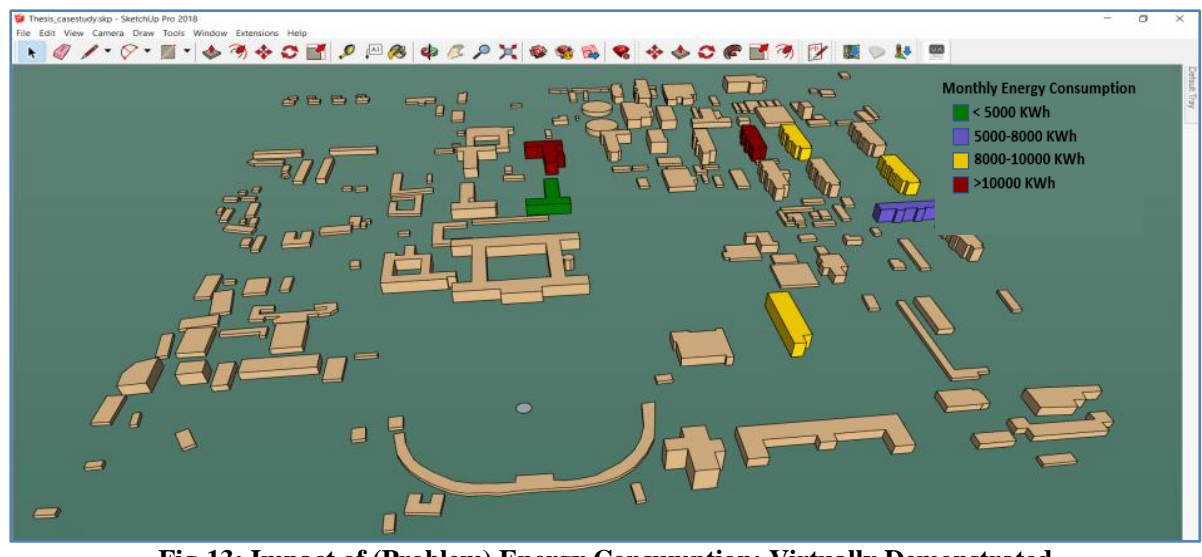

Fig-13: Impact of (Problem) Energy Consumption: Virtually Demonstrated

Now, its application is demonstrated by extending and scaling it to a city level. Since the data for all the buildings are not readily available, a dummy data set on Ur, Uw, area of the opening, and area of the wall are randomly created. The other data such as building footprints are obtained from the GIS map, the height and floor areas are from building inventory, and the weather data are from a sensor; however, the reliability of data is limited, it is only for demonstration. The AI tool integrated with the 3D model, as shown in Figure 14, learns the patterns of energy consumption from a database of seven buildings considering building properties and the weather parameter and develops a cognitive skill to predict the energy consumption of other buildings as shown in Figure 15.

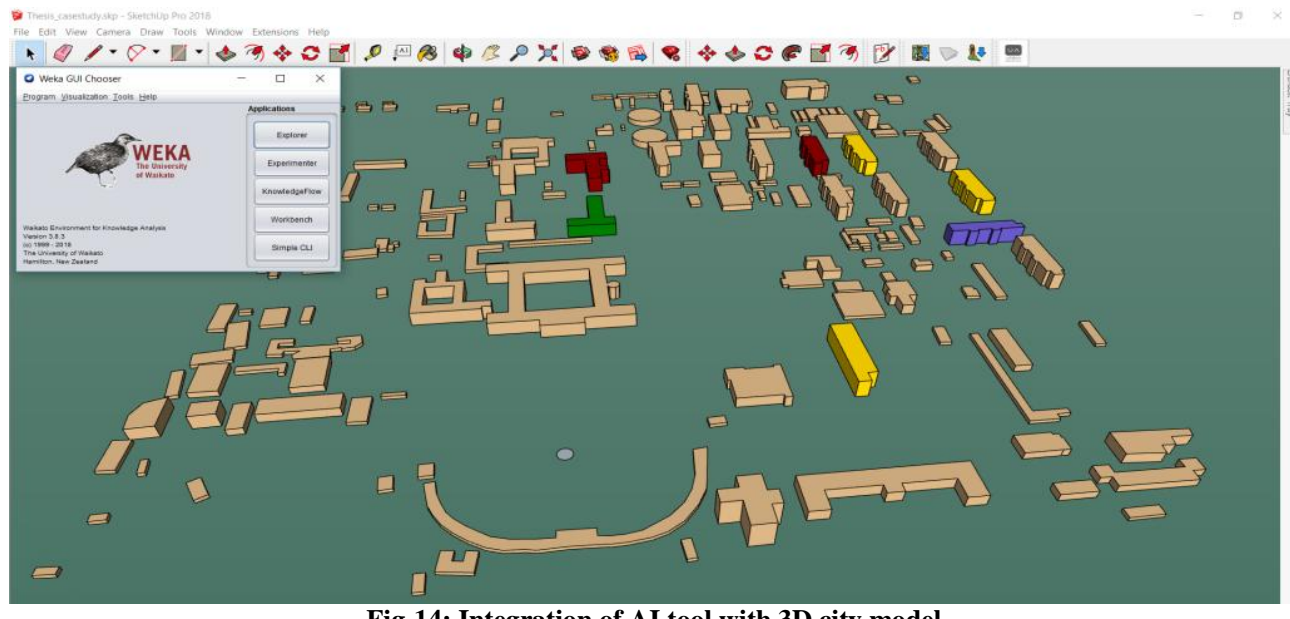

Fig-14: Integration of AI tool with 3D city model 


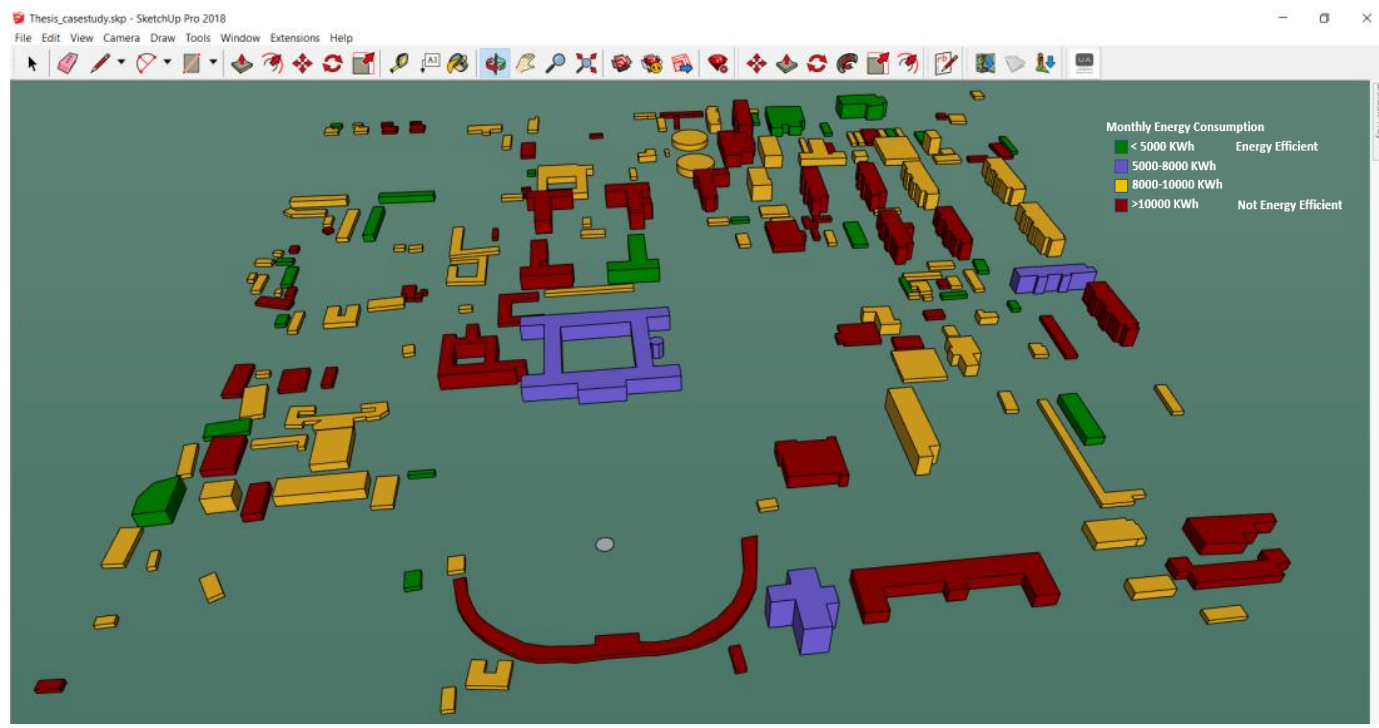

Fig-15: Visualization of Building Energy Consumption at the city level which is predicted by AI

The use of GIS-BIM-AI can geolocate any building with its energy efficiency within a very short time. The most energy-efficient buildings are shown in green color whereas dark red color signifies the most energy-consuming buildings. The same procedure can be applied to study the effectiveness of solutions for problems. Suppose if the facility manager wants to retrofit the building to make it energy efficient with a solar panel on a roof, the impacts of solution or simulation of future based on scenario (what-if) analysis can also be virtually demonstrated for the decision making. Figure 16 shows the average monthly capacity of each building to generate solar energy, considering the solar panel efficiency of $15 \%$, total solar panel area as $50 \%$ of roof area, the performance ratio of 0.75 , and average monthly solar radiation of $189.96 \mathrm{w} / \mathrm{m}^{2}$ (excluding shading). The facility management operating platform based on the GIS-BIMAI framework identifies a problem, generates its solution, and provides feedback to stakeholders. The stakeholders then discuss whether the impact meets their requirements for decision making.

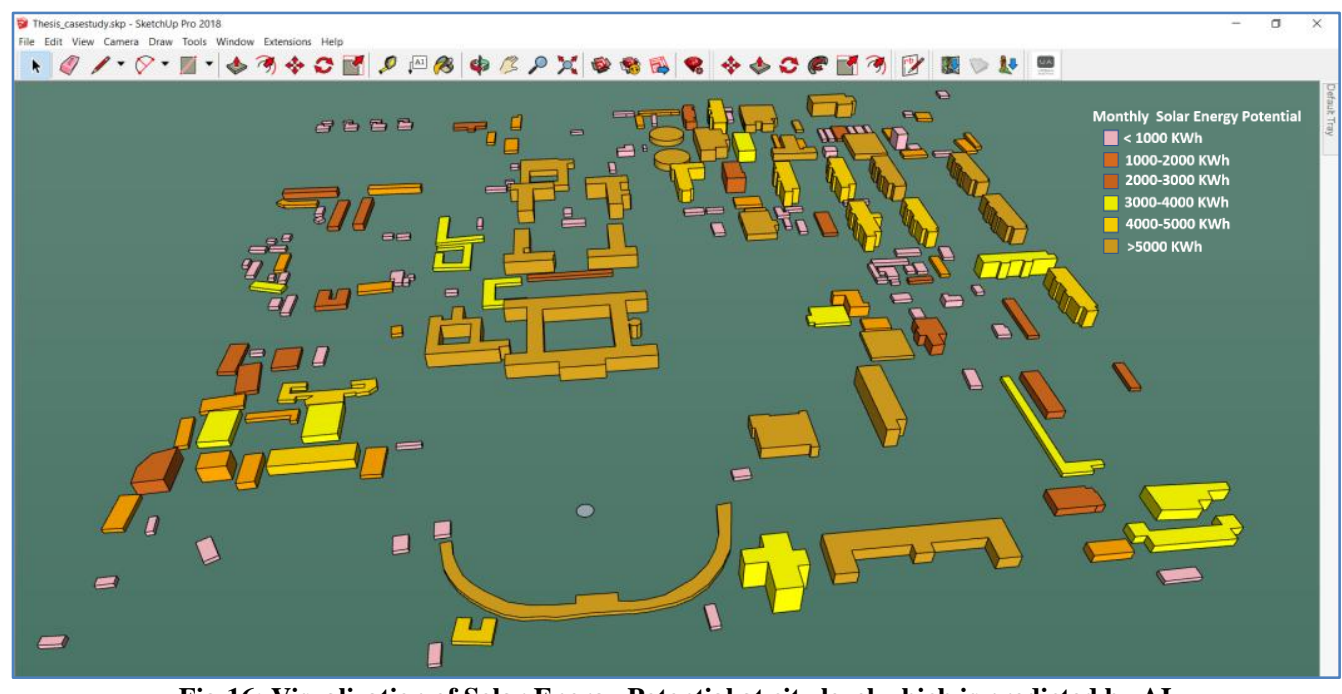

Fig-16: Visualization of Solar Energy Potential at city level which is predicted by AI

(3) Dynamic Modelling: The demonstration of dynamic modeling is not considered in this research; however, the concept can be used for any anomaly detection, leakage detection, repair and maintenance, and control building facilities such as heating and cooling to prevent the failure of the facility. It can give early warning related to the condition of facilities by comparing real-time data with historical data. The information displayed could be in the form of colors, notifications, and beeps. Then the stakeholders can make an assessment and control the facility to provide uninterrupted services in a very short time. Thus, the Control and Communication layer can answer the queries; quantify the result of big data, real-time data, and the impacts of the urban analytics layer in an interactive way. 


\section{CONCLUSION}

A Smart city is considered as an innovation to solve urban issues such as traffic congestion, and, environmental degradation, which are the consequences of rapid urbanization. Recent researchers are concentrated on making a city sustainable and resilient via smart technologies. Many researchers have claimed facility management is the key to tackle those inefficiencies and can prevent wastage, cost, and time; however, with the advent of the $4^{\text {th }}$ industrial revolution managing facilities is one of the biggest challenges. Current facilities management systems have problems such as heterogeneous data integration in the single platform, inefficient tools to process big data, inefficiency in a facility management team, and a problem on effective communication for decision making.

This research develops a conceptual framework of facility management in smart cities to address those issues. The framework consists of the integration of a $3 \mathrm{D}$ virtual city model with AI. The findings emphasize that the GIS-BIM-AI framework develops an interactive, content-rich $3 \mathrm{D}$ city model where the stakeholders can find any data relevant to them, ask any queries, run any analysis, and visualize the impacts and collaborate with any team members with different background to improve the quality of life. The results from the case study demonstrated that its feature of integrating real-time data into the analysis of facility conditions is a key factor for early impact assessment, allocating resources efficiently, and help in well-informed decision making. It enables the city-wide simulation to solve urban problems such as energy demand management. The key benefits are efficiency gains, knowledge sharing, and cost savings, and the visualization of dynamic data improves citizen engagement that improves the quality of life and transparency in decision making. The proposed conceptual framework for Facility Management in a smart city:

- Collects heterogeneous data and integrates into the single 3D virtual city repository prevents the cost and time in recollecting the data.

- Allows the facility managers to learn, adapt, and optimize the operation cost.

- Creates a predictive analysis to identify the failure of the system, the scenario analysis to solve the problem with immediate feedback.

- Has a visualization platform that enables interaction of facilities with stakeholders, promotes citizens' engagement, and reduces monitoring costs.

- Helps in real-time monitoring, evaluation of facilities performance under a different scenario provides immediate feedback; thus, enabling the stakeholders to control the facilities with well-informed information.
- Shows basic Interoperability among the GISBIM-AI.

All of these features improve the quality of services and customer satisfaction, save resources, cost, and time which is the universal principle of sustainability. Ruohomaki et al. [27] and Kan and Anumba [28] have also highlighted the role of Digital Twin platform in making a city smart and sustainable; however, they were not sure what type the type of sensing technology can precisely collect data, how to aggregate the data throughout the life cycle of the project and how to achieve seamless heterogeneous data integration and interoperability among the devices. The GIS-BIM-AI integrated with IoT and its demonstration on facility management in the real world validate the hypothesis that the Digital Twin platform integrated with AI is a solution for sustainable smart city development.

This research is expected to contribute the body of knowledge by demonstrating the effectiveness of the Digital Twin model with IoT and AI for a smart and sustainable city. The development of a smart city operating platform for FM with $\mathrm{AI}$ is the most important achievement. Since the framework is validated with case-studies from developing countries, it is also an opportunity for developing countries to make leapfrog in smart city development initiatives. The take-home message is a smart city is not only about developing the new infrastructures, but it's also about managing the existing infrastructures, and even a small city can be smarter.

As per the scope, the concept has been validated in the case of FMIS and energy demand management in a city. Because of the limited time in this study, the data used in the case study is basically to demonstrate the process rather than the accuracy. The interpretation of results from case studies is only a generalization. Future researchers can collect more accurate static and dynamic data with more attributes and evaluate the proposed methodology. The current methodology is only a conceptual framework based on basic skills in 3D modeling, $\mathrm{AI}$, and programming; however, future researchers can modify the framework to make it more interactive with more automation. There is also a need to validate the concept on other components of smart cities such as ITS and a larger scale with micro-level details, for example, building interior, and anomaly detection with a web-based visualization technique.

Funding: This research received no external funding.

Conflicts of Interest: The authors declare no conflict of interest. 
systems. Journal of Computing in Civil Engineering, 33(3), 04019008.

5. Goulden, M., \& Spence, A. (2015). Caught in the middle: The role of the Facilities Manager in organisational energy use. Energy Policy, 85, 280287.

6. Curtis, J., Walton, A., \& Dodd, M. (2017). Understanding the potential of facilities managers to be advocates for energy efficiency retrofits in mid-tier commercial office buildings. Energy policy, 103, 98-104.

7. Tsai, M. H., Kang, S. C., \& Hsieh, S. H. (2014). Lessons learnt from customization of a BIM tool for a design-build company. Journal of the Chinese Institute of Engineers, 37(2), 189-199.

8. Chaturvedi, K., Matheus, A., Nguyen, S. H., \& Kolbe, T. H. (2019). Securing spatial data infrastructures for distributed smart city applications and services. Future Generation Computer Systems, 101, 723-736.

9. Xue, F. Study on the Evaluation Model and Path for Smart City. In ICCREM 2017 (pp. 415-425).

10. Liu, Y., Wang, H., \& Tzeng, G. H. (2018). From measure to guidance: Galactic model and sustainable development planning toward the best smart city. Journal of Urban Planning and Development, 144(4), 04018035.

11. Agrawal, G. (2017). Securing the Rights of Pedestrians Is the Key to Smart, Sustainable Cities: A Law and Policy Approach. In International Conference on Sustainable Infrastructure 2017 (pp. 354-366).

12. Michalec, A. O., Hayes, E., \& Longhurst, J. (2019). Building smart cities, the just way. A critical review of "smart" and "just" initiatives in Bristol, UK. Sustainable Cities and Society, 47, 101510.

13. Silva, B. N., Khan, M., \& Han, K. (2018). Towards sustainable smart cities: A review of trends, architectures, components, and open challenges in smart cities. Sustainable Cities and Society, 38, 697-713.

14. Wang, Z. J., Liu, Y., \& Chen, F. (2018). Evaluation and improvement of the interchange from bus to metro using smart card data and GIS. Journal of Urban Planning and Development, 144(2), 05018004.

15. Gupta, K., Yang, Z., \& Jain, R. K. (2019). Urban data integration using proximity relationship learning for design, management, and operations of sustainable urban systems. Journal of Computing in Civil Engineering, 33(2), 04018063.

16. Ma, Z., \& Ren, Y. (2017). Integrated application of BIM and GIS: an overview. Procedia Engineering, 196, 1072-1079.

17. Ahmad, M. W., Mourshed, M., \& Rezgui, Y. (2017). Trees vs Neurons: Comparison between random forest and ANN for high-resolution prediction of building energy consumption. Energy and Buildings, 147, 77-89.
18. Li, Q., Wu, Z. Y., \& Rahman, A. (2019). Evolutionary deep learning with extended Kalman filter for effective prediction modeling and efficient data assimilation. Journal of Computing in Civil Engineering, 33(3), 04019014.

19. Hou, J., Kan, Ni., \& Ayman, H. (2019). An Artificial Neural Network Based Anomaly Detection Algorithm for Nuclear Power Plants. Transactions 120, no. 1, 219-222.

20. Demolli, H., Dokuz, A. S., Ecemis, A., \& Gokcek, M. (2019). Wind power forecasting based on daily wind speed data using machine learning algorithms. Energy Conversion and Management, 198, 111823.

21. Baird, G. M., Hatler, D., \& Carpenter, P. (2019). How Cost Effective Is Machine Learning/AI Applied to Leak Detection and Pipe Replacement Prioritization?. In Pipelines 2019: Multidisciplinary Topics, Utility Engineering, and Surveying (pp. 274-283). Reston, VA: American Society of Civil Engineers.

22. Cao, Y., Song, X., \& Wang, T. (2015). Development of an energy-aware intelligent facility management system for campus facilities. Procedia engineering, 118, 449-456. DOI: 10.1016/j.proeng.2015.08.446

23. Carvalho, T. P., Soares, F. A., Vita, R., Francisco, R. D. P., Basto, J. P., \& Alcalá, S. G. (2019). A systematic literature review of machine learning methods applied to predictive maintenance. Computers \& Industrial Engineering, 137, 106024.

24. Correa, F. R. (2015). Is BIM big enough to take advantage of big data analytics?. In ISARC. Proceedings of the International Symposium on Automation and Robotics in Construction (Vol. 32, p. 1). IAARC Publications.

25. Chaturvedi, K., \& Kolbe, T. H. (2019). A requirement analysis on extending semantic $3 d$ city models for supporting time-dependent properties. ISPRS Annals of Photogrammetry, Remote Sensing \& Spatial Information Sciences, 4.

26. Carvalho, T. P., Soares, F. A., Vita, R., Francisco, R. D. P., Basto, J. P., \& Alcalá, S. G. (2019). A systematic literature review of machine learning methods applied to predictive maintenance. Computers \& Industrial Engineering, 137, 106024.

27. Ruohomäki, T., Airaksinen, E., Huuska, P., Kesäniemi, O., Martikka, M., \& Suomisto, J. (2018, September). Smart city platform enabling digital twin. In 2018 International Conference on Intelligent Systems (IS) (pp. 155-161). IEEE.

28. Kan, C., \& Anumba, C. J. (2019). Digital twins as the next phase of cyber-physical systems in construction. In Computing in civil engineering 2019: Data, sensing, and analytics (pp. 256-264). Reston, VA: American Society of Civil Engineers. 